\title{
Synergistic antibacterial effect of apigenin with $\beta$-lactam antibiotics and modulation of bacterial resistance by a possible membrane effect against methicillin resistant Staphylococcus aureus
}

\author{
K. Akilandeswari ${ }^{1}$, K. Ruckmani ${ }^{1,2^{*}}$

\begin{abstract}
'Department of Pharmaceutical Technology, Centre for Excellence in Nanobio Translational Research (CENTRE), Bharathidasan Institute of Technology, Anna University, Tiruchirappalli - 620 024, Tamilnadu, India

${ }^{2}$ DST Sponsored National Facility for Drug Development for Academia, Pharmaceutical and Allied Industries, Bharathidasan Institute of
\end{abstract} \\ Technology, Anna University, Tiruchirappalli 620 024. Tamilnadu, India
}

\begin{abstract}
Methicillin-resistant Staphylococcus aureus (MRSA) infections are easily spread among infected patients, where resistance has dramatically increased resulted in serious health issues. Therefore, there is a need to develop alternative natural or combination drug therapies. Apigenin (AP) is a natural poly phenolic flavonoid has been found to possess many beneficial biological actions. The aim of this study was to investigate the anti-MRSA efficacy and synergistic effect of apigenin (AP) and in combination with ampicillin (AM) and ceftriaxone (CEF). The antibacterial activity of apigenin was assessed by the broth macro dilution, checkerboard micro dilution method and time-kill assay. The mode of action was studied by outer and inner membrane permeabilisation assays, scanning electron microscopy and transmission electron microscopy. The minimum inhibitory concentration (MIC) of apigenin against gram positive and gram negative strain ranged from 32.5 to $62.5 \mu \mathrm{g} / \mathrm{ml}$. In checkerboard method apigenin markedly reduced the MIC of the antibiotics ampicillin $800 \mu \mathrm{g} / \mathrm{ml}$ shifted to $107 \mu \mathrm{g} / \mathrm{ml}$ (AM+AP) and ceftriaxone 58 $\mu \mathrm{g} / \mathrm{ml}$ shifted to $2.6 \mu \mathrm{g} / \mathrm{ml}(\mathrm{CEF}+\mathrm{AP})$ against MRSA. The synergistic activity of ampicillin and ceftriaxone plus apigenin combinations with FIC indices (CI) between $0.18-0.47$. The modulation of methicillin-resistance by apigenin significantly enhanced the activities of ampicillin and ceftriaxone. The result of time-kill assays of the two drug combinations AM +AP and CEF+AP against MRSA showed significant inhibitory effect and reduced the colony count by approximately $99 \%$ after $8 \mathrm{~h}$ The results for outer membrane (OM) and inner membrane (IM) permeabilization showed that ampicillin and ceftriaxone in combination with apigenin damaged MRSA cytoplasmic membrane and caused subsequent leakage of intracellular constituents. Electron microscopy clearly showed that the above said combination also caused marked morphological damage of cell wall, cell shape and plasma membrane of this strain. From these results, it can be concluded that apigenin has the synergistic effect with ampicillin and ceftriaxone to reverse bacterial resistance against MRSA.
\end{abstract}

Key words: MRSA, Microbial resistance, Synergistic activity, Apigenin, Ampicillin, Ceftriaxone, Inner membrane permeability and Outer membrane permeability assay.

\section{Introduction}

Methicillin-resistant Staphylococcus aureus (MRSA) is a major pathogen causing nosocomial infection, commonly found in nature as well as in normal skin, the nasal cavity, and oral cavity, which remains a frequent cause of morbidity and mortality in hospital-acquired infections (1). MRSA causes bloodstream infections, pneumonia, skin infections and wound suppuration that eventually lead to sepsis and fatalities. Clinical survey from the U.S Center for Disease Control and Prevention, were reported severe MRSA infection cases 80,461 annually with 11,285 deaths per year in United States (CDC 2013) the threat report by in Malaysian hospitals. Infection cases reported between the year 2002 and 2007 were showing an increasing trend with annual MRSA prevalence over $40 \%$ (2-4). In general, MRSA is sensitive to antibiotics, however, recent reports in the food industry have suggested an increasing resistance to antibiotics in MRSA, Salmonella and Escherichia coli bacterium. The antibiotic-resistant bacteria have developed in the past decades leading to various difficulties in treating infectious diseases. Many no of antibiotics were used in the management of S.aureus infections specifically $\beta$-lactam antibiotics penicillin and ampicillin but rapidly developing resis- tant throughout continuous therapy. This is due to the $\beta$-lactamase enzyme inactivates $\beta$-lactam ring of penicillin and ampicillin structure and also due to the presence of mec A gene (5-9). In that harm situation, recent emergence of multi drug resistant (MDR) strains threatens the susceptible humans throughout the world; therefore researchers continue to search for novel antibacterial compounds in various ways. Many plant extracts and spices are reported to possess phenolic phytochemicals such as phenolic acids, ellagic acid, flavonoids, and proanthocyanidins. These compounds showed positive health benefits, especially antimicrobial potential, against diverse microorganisms. Recently, many scientific data have suggested that these polyphenolic compounds in combination with antibiotics have antibacterial action. Plant-derived compounds are potential sources for combinations. Flavonoids are known to be

Received September 12, 2016; Accepted December 25, 2016; Published December 30, 2016

* Corresponding author: Kandasamy Ruckmani, Department of Pharmaceutical Technology, Bharathidasan Institute of Technology, Anna University, Tiruchirappalli-620024. Tamilnadu, India. Email: hodpharma@ gmail.com

Copyright: (C) 2016 by the C.M.B. Association. All rights reserved. 
one of the sources of beneficial compounds for many infectious diseases, including antibacterial agents. These compounds in combination with antibiotics have been reported to have antibacterial action against bacterial resistance (5-9).

Therefore, novel flavonoids or new group of phyto pharmaceutical approaches that show synergistic effect with antibacterial agents. In this study, we have investigated the in vitro activity of naturally occurring plant flavone Apigenin (AP) chemically it is 4, 5, 7,-trihydroxyflavone, which is richly present in common fruits such as grapefruit, plant-derived beverages, medicinal plants and vegetables. AP has been shown to possess remarkable anti-bacterial, anti-inflammatory, anti-oxidant and anti-carcinogenic properties (10). However, no studies have reported any synergistic effects of Apigenin (AP) with Ampicillin (AM) and Ceftriaxone (CEF) and the reputed mechanism of antibacterial effects of AP against MRSA. Therefore, our study was focused on the evaluation of in vitro antibacterial activity of phenolic flavonoid AP alone and in combination with antibiotic AM and CEF determined by means of combination index $(\mathrm{CI})$ value.

\section{Materials and Methods}

\section{Preparation of chemicals and media}

Ampicillin(AM), ciprofloxacin (CP), ceftriaxone (CEF), apigenin(AP) and crystal violet were obtained from sigma aldrich, Germani stock solution were prepared with suitable solvents at the required concentration. Nutrient broth (NB), Nutrient agar (NA), Muller Hinton broth (MHB), Muller Hinton agar (MHA), Brain heart infusion broth (BHI), Brain heart infusion agar (BHA) were obtained from himedia laboratories, Mumbai.

\section{Bacterial strains}

Staphylococcus aureus NCIM 2079, Klebsiella pneumonia NCIM 2719, Enterobacter cloacae NCIM 2164 were obtained from National collection of industrial microorganisms (NCIM), Pune, MRSA, clinical strains Enterococcus faecalis and Staphylococcus aureus were obtained from KAP Viswanathan medical college, Tiruchirappalli. All microbial strains were stored in refrigerator and frozen at $-70^{\circ} \mathrm{C}$ before use. The stored bacterial strains were suspended in MHB and incubated at $37^{\circ} \mathrm{C}$ for $24 \mathrm{~h}(11)$.

\section{Determination of minimum inhibitory concentration for apigenin and selected antibiotics}

The selected test agents initially underwent efficacy determination specifically minimum inhibitory concentration against different strains. Our study specifically focused on MRSA, moreover gram positive and gram negative organisms were also included to determine the efficacy of apigenin against other strains too. Twenty four hours culture of $S$. aureus NCIM 2079, K. pneumonia NCIM 2719\& E. cloacae NCIM 2164 and clinical strains $E$. faecalis \& clinical strain MRSA were taken to analyse the inhibitory effect of the antibiotics AM $\&$ CEF and AP. Different concentrations of $1000 \mu \mathrm{g} /$ $\mathrm{ml}$ stock solution of antibiotics and AP were prepared. The prepared stock solutions were used for MIC determination as per the standard procedure in tube dilution method (11). All the tubes containing test agents were incubated for 24 hours at $37^{\circ} \mathrm{C}$. The test tubes were then observed for turbidity with a naked eye and the impact was calibrated by determining optical density by measuring absorbance at $600 \mathrm{~nm}$ in a UV-visible spectrophotometer (UV -Thermo Scientific BIOMATE 35). The lowest concentration of drugs in a tube or plate that failed to show any visible macroscopic growth was considered as its MIC. The experiments were performed in triplicates for each bacterial species and were repeated wherever necessary (11).

\section{Checker board method- Combination index deter- mination for $\mathrm{AM}, \mathrm{CEF}, \mathrm{AP}, \mathrm{AM}+\mathrm{AP}$ and $\mathrm{CEF}+\mathrm{AP}$ against MRSA}

According to the results obtained from MIC the interactions of two drugs AM or CEF with AP $(\mathrm{AM}+\mathrm{AP}$ and $\mathrm{CEF}+\mathrm{AP}$ ) against MRSA was determined, the most frequently used procedure is the checker-board method. In this technique, aliquots of log-phase bacterial cultures ( $0.5 \mathrm{McF}$ arland standard) are transferred to microtiter plates containing different concentrations of drugs- AM at 12.5 to $800 \mu \mathrm{g} / \mathrm{mL}$; $\mathrm{CEF}$ at 0.125 to 32 $\mu \mathrm{g} / \mathrm{mL} ; A P$ at 1 to $256 \mu \mathrm{g} / \mathrm{mL}$, and in the ratio of $1: 25$ combination of AM+AP, $0.48-15.36 \mu \mathrm{g} / \mathrm{mL}$ AP with 12 to $384 \mu \mathrm{g} / \mathrm{mL}$ of $\mathrm{AM}$, and in ratio of $1: 3$ combination of $\mathrm{CEF}+\mathrm{AP} 0.125$ to $16 \mu \mathrm{g} / \mathrm{mL} \mathrm{CEF}$ with 0.375 to 48 $\mu \mathrm{g} / \mathrm{mL}$ AP. Synergistic combination index was calculated in isobologram software. The two combination test samples; AM with AP and CEF with AP were graphically represented by dose effect curve, combination index value, dose reduction index and isobole method which was interpreted in isobologram software $(10,12,13,14)$. Preparation of micro plates -

The petriplates were prepared and inoculated on the same day, as certain drugs tend to inactivate each other if stored together.

\section{i. Microplate organization:}

- column 1 is antibiotics AM or CEF alone

- column 2 - 7 contain combinations

- column 8 is organism control

- column 9 is medium control

- row 1 is AP alone

\section{ii. Dilution of antibiotic and drugs}

The standard concentration of antibiotics AM, CEF and AP were thawed after storage. Micro wells were dispensed with $100 \mu \mathrm{l}$ of MHB, then carry out required dilutions with $50 \mu \mathrm{l}$ of stock solution of antibiotics AM or CEF and AP.

\section{iii. Inoculation}

An overnight culture of MRSA was diluted in MHB to achieve OD based inoculum of $1 \times 10^{5}-5 \times 10^{5}$. Then all the wells were inoculated (except column 12 which is considered as blank) with $50 \mu 1$ of the diluted organism (the volume in each well should be $200 \mu \mathrm{l}$ ).

The combination index is defined as synergy when the $\mathrm{CI}$ index ranges $\leq 0.5$, indifference is defined when $\mathrm{CI}$ index is $>0.5$, but when the $\mathrm{CI}$ index value is $\leq 1-$ 4.0 it is defined as antagonism $(10,12,13)$. The growth inhibition was measured by determining the absorbance at $600 \mathrm{~nm}$ in a multi-mode microplate reader (Enspire, 
Perkin Elmer, USA). From these readings, combinations index values were determined and the synergistic, additive interactions were calculated.

Dose effect was calculated from the following formula,

Absorbance of positive control (without drug) - Absorbance of test solution Absorbance of positive control

The percentage inhibition of each drug and its combination was obtained from dose effect value multiplied with 100 . The combination index value was determined from the following formula

$\mathrm{CI}=\frac{\text { MIC of substance } \mathrm{A} \text { in combination }}{\text { MIC of substance } \mathrm{A} \text { alone }}+\frac{\text { MIC of substance } \mathrm{B} \text { in combination }}{\text { MIC of substance } \mathrm{B} \text { alone }}$

Where CI - Combination index; Substance A denotes MIC of AM or CEF; substance B denotes MIC of AP.

Calculation of the median-effect concentration $\left(\mathrm{IC}_{50}\right)$ or the median -effect dose $\left(\mathrm{ED}_{50}\right)$ is a usual method in medical sciences. The old arbitrary method was to draw the empirical best-fit curve and then predict $\mathrm{IC}_{50}$ or $\mathrm{ED}_{50}$ value from the empirical curve. The goodness of fit to the straight line can be determined by the linear correlation coefficient ( $\mathrm{r}$ value) calculated from $\mathrm{x}$ and $\mathrm{y}$ intercept which represent $y=a x+b$.

A plot $x=\log (D)$ Vs $y=\log (f a / f u)$.

$\mathrm{fa}+\mathrm{fu}=1$, fu $=1$-fa where fa-fraction affected, fu-fraction unaffected

Dose reduction index (DRI) was calculated from the following equation where (Dx) is the dose of drug 1 alone that inhibits $\mathrm{x} \%$.

DRI can be really obtained from the reciprocal of each term of the CI equation thus,

$(\mathrm{DRI})_{1}=\left(\mathrm{D}_{\mathrm{x}}\right)_{1} /(\mathrm{D})_{1}$

$(\mathrm{DRI})_{2}=\left(\mathrm{D}_{\mathrm{x}}\right)_{2} /(\mathrm{D})_{2}$

DRI $>1$ and $<1$ indicate favorable and not favorable dose reduction; DRI $=1$ indicates no dose reduction.

\section{Time kill analysis for apigenin with ampicillin and ceftriaxone}

The rate of antibacterial action and synergistic effect of AM + AP and CEF + AP were determined by using time kill assay. The bacterial culture was inoculated in $\mathrm{BHI}$ and incubated at $37^{\circ} \mathrm{C}$ for $24 \mathrm{~h}$ after which the culture was diluted with saline solution at a concentration of $1 \times 10^{6} \mathrm{cfu} / \mathrm{ml}$. The test samples AM, CEF, AP, AM $+\mathrm{AP}$ and $\mathrm{CEF}+\mathrm{AP}$ were added to the bacterial suspensions at different concentrations and then incubated at $37^{\circ} \mathrm{C}$. The final concentration was $5 \times 10^{5} \mathrm{cfu} / \mathrm{ml}$. DMSO was used as a negative control. $0.1 \mathrm{ml}$ of the incubated culture was removed at time interval of two hours ranging from $0-18 \mathrm{~h}$ from the time of incubation and was subjected to 10 -fold dilution using normal saline. Then $20 \mu 1$ of each dilution was cultured on MHA and the number of viable colonies was calculated at $18 \mathrm{~h}$ incubation. Colony counts were performed on plates and $30-300$ colonies were enumerated. The antimicrobial agents used were considered bactericidal at the lowest concentration that reduced the original inoculum by 3 $\log 10 \mathrm{CFU} / \mathrm{ml}(99.9 \%)$ for each of the indicated times. On the other hand, they were considered bacteriostatic if the inoculum was reduced by $0-3 \log 10 \mathrm{CFU} / \mathrm{ml}$. The antibacterial synergistic effect was considered as when the $\mathrm{CFU} / \mathrm{ml}$ is reduced to $>2 \log 10(15)$.

\section{Outer membrane permeabilisation assay-crystal} Violet assay

The mode of antibacterial action of AM, CEF, AP, $\mathrm{AM}+\mathrm{AP}$ and $\mathrm{CEF}+\mathrm{AP}$ were determined by studying the alteration of membrane permeability by the crystal violet assay (10). To the one day old MRSA suspension at $0.5 \mathrm{McF}$ arland standard, the test agents were added at a concentration as follows, individual test agents: $800 \mu \mathrm{g} / \mathrm{ml}$ of AM, $35 \mu \mathrm{g} / \mathrm{ml}$ of CEF, $60 \mu \mathrm{g} / \mathrm{ml}$ of AP and combinations, $100 \mu \mathrm{g} / \mathrm{ml}$ of AM with $5 \mu \mathrm{g} / \mathrm{ml}$ of AP, $3 \mu \mathrm{g} / \mathrm{ml}$ of CEF with $8 \mu \mathrm{g} / \mathrm{ml}$ of AP. Control samples were prepared similarly without treatment $(10,13)$. The cells were harvested at $9300 \times \mathrm{g}$ for 5 min after which they were resuspended in PBS containing $10 \mu \mathrm{g} / \mathrm{ml}$ of crystal violet. The cell suspension was then incubated for $10 \mathrm{~min}$ at $37^{\circ} \mathrm{C}$. The suspension was then centrifuged at $13,400 \times \mathrm{g}$ for $15 \mathrm{~min}$ and the OD at $590 \mathrm{~nm}$ of the supernatant was measured in UV-VIS spectrophotometer (UV-Thermo Scientific BIOMATE 35). The OD value of the crystal violet solution was taken and it was considered as $100 \%$. The percentage of crystal violet uptake of all the samples was calculated using the following formula:

$$
=\frac{\text { OD value of the sample }}{\text { OD value of crystal violet solution }} \times 100
$$

\section{Inner-membrane permeabilization assay-UV at $260 \mathrm{~nm}$}

The UV-absorbing material releases in the microbial cells' were calculated by UV-Visible spectrophotometer. To the one day old MRSA suspension at $0.5 \mathrm{McFar}-$ land standard the test agents were added at a concentration as follows, individual test agents: $800 \mu \mathrm{g} / \mathrm{ml}$ of AM, $35 \mu \mathrm{g} / \mathrm{ml}$ of CEF, $60 \mu \mathrm{g} / \mathrm{ml}$ of AP and under combinations, $100 \mu \mathrm{g} / \mathrm{ml}$ of AM with $5 \mu \mathrm{g} / \mathrm{ml}$ of AP, $3 \mu \mathrm{g} / \mathrm{ml}$ of CEF with $8 \mu \mathrm{g} / \mathrm{ml}$ of AP. Control samples were prepared similarly without treatment $(10,13)$. All the samples were incubated at $37^{\circ} \mathrm{C}$ for $60 \mathrm{~min}$. After treatment, the cell suspension was centrifuged at $13,400 \times \mathrm{g}$ for $15 \mathrm{~min}$ and the OD260 value of the supernatant was taken as a percentage of the extracellular UV-absorbing materials released by cells. All the measurements were done in triplicate in UV-VIS spectrophotometer (UV-Thermo Scientific BIOMATE 35) (10,13).

\section{Cell wall damage analysis by SEM}

SEM observation was carried out on MRSA cells. MRSA cell suspension at the concentration of 0.5 McFarland standard was inoculated on a MHA plate and incubated at $37^{\circ} \mathrm{C}$ for $12 \mathrm{~h}$. The $\mathrm{AM}+\mathrm{AP}$ and $\mathrm{CEF}+\mathrm{AP}$ at the required concentration was added onto the inoculated agar and further incubated for another $36 \mathrm{~h}$ at the same temperature. The untreated culture was used as a control. A small block of MRSA containing agar was withdrawn from the inoculated plate at 0 and $36 \mathrm{~h}$, coated with gold, and viewed under SEM. The SEM study was done under the following analytical conditions: $\mathrm{L}=$ $\mathrm{SE} 1, \mathrm{WD}=21 \mathrm{~mm}$, and EHT $=10.0 \mathrm{kV}$ (Vega 3, Tescan, USA edx: Bruker Nano, Germany) (23).

\section{Transmission electron microscopy (TEM)}

MRSA subculture was prepared to examine the cell wall by TEM FEI, Tecnai G2,T12, Germany and followed the standard protocol (10). The combination of 
Table 1. Anti bacterial activity of plant extracts against selected strains determined by MIC.

\begin{tabular}{ccccc}
\hline \multirow{2}{*}{ S.No } & \multirow{2}{*}{ Name of the bacterial strains } & \multicolumn{3}{c}{ MIC of Antibiotics and AP in $\boldsymbol{\mu g} / \mathbf{m l}$} \\
\cline { 3 - 5 } & & AM & CEF & AP \\
\hline 1 & S. aureus NCIM 2079 $(\mu \mathrm{g} / \mathrm{ml})$ & 125 & 15.6 & 31.25 \\
2 & Klebsiella pneumoniae NCIM $2719(\mu \mathrm{g} / \mathrm{ml})$ & 125 & 15.6 & 31.25 \\
3 & Enterobactor clocea NCIM $2164(\mu \mathrm{g} / \mathrm{ml}$ & 125 & 15.6 & 31.25 \\
4 & Clinical strain Enterococcus faecalis $(\mu \mathrm{g} / \mathrm{ml})$ & 1000 & 62.5 & 62.5 \\
5 & MRSA clinical strain $(\mu \mathrm{g} / \mathrm{ml})$ & & & \\
\hline
\end{tabular}

All the values represented as triplicates.

$\mathrm{AM}+\mathrm{AP}$ and $\mathrm{CEF}+\mathrm{AP}$ that dramatically decreased the MIC when added to the MRSA culture was chosen for electron microscopy study.

\section{Results}

The MIC of AM, CEF and AP exhibited broad spectrum of antibacterial activity against both gram positive and gram negative organisms against clinical and reference strains in the MIC values between 7.8 to 1000 $\mu \mathrm{g} / \mathrm{ml}$ shown in Table 1 .

\section{Synergistic effect determined for AM, AP and AM+AP against MRSA}

The checkerboard method was used to determine the synergistic activity for the combination of natural flavonoid AP individually and in combination with AM and CEF against MRSA strain. The interactions were interpreted and its growth inhibition was found using this combination index values denoted in Table 2. The observed values from checker board dilution of twodrug combination between AP and in combination with AM and CEF were plotted as dose effect curve, logarithmic combination index value, dose reduction index values and isobologram denoted in figure 1a-d, 2a-d. A predominant synergism was also detected when AP and in combination with $\mathrm{AM}$ and $\mathrm{CEF}$ and its inhibition was determined by ED 50, ED90 and its corresponding CI values were calculated in table 2 .

The bacterial growth inhibitory effect of AM, AP and AM+AP on MRSA was observed and interpreted. From the following formula, fraction affected and fraction unaffected was calculated and the dose effect curve was plotted using isobologram software.

\section{Individual}

- $\quad$ AM - 12.5 to $800 \mu \mathrm{g} / \mathrm{ml}$;

- AP at $1-64 \mu \mathrm{g} / \mathrm{ml}$

Combination

$\mathrm{AM}+\mathrm{AP}(25: 1)-12-384 \mu \mathrm{g} / \mathrm{ml}$ of AM with $0.48-$ $15.36 \mu \mathrm{g} / \mathrm{ml}$ of AP.

The CI values of the combined drugs AP, AM and $\mathrm{AP}+\mathrm{AM}$ were calculated using the formula and its re-

Table 2. Combination index value determined for AM, AP and AM+AP against MRSA.

\begin{tabular}{|c|c|c|c|c|c|c|c|c|c|}
\hline \multirow{2}{*}{$\begin{array}{c}\text { Drug/ } \\
\text { Combination } \\
\text { against MRSA }\end{array}$} & \multicolumn{3}{|c|}{ Fraction affected $50 \%$} & \multicolumn{3}{|c|}{ Fraction affected $75 \%$} & \multicolumn{3}{|c|}{ Fraction affected $90 \%$} \\
\hline & $\begin{array}{c}\text { CI value } \\
\text { (FIC) }\end{array}$ & Drug & ation in & $\begin{array}{c}\text { CI value } \\
\text { (FIC) }\end{array}$ & Drug & $\begin{array}{l}\text { ntration } \\
\text { ml }\end{array}$ & $\begin{array}{c}\text { CI value } \\
\text { (FIC) }\end{array}$ & Drug & $\begin{array}{l}\text { itration } \\
\text { nl }\end{array}$ \\
\hline AP & & 5.19 & & & 17.6 & & & 57.5 & \\
\hline $\mathrm{AM}$ & & & 173.99 & & & 373.2 & & & 800.5 \\
\hline APAM & 0.47 & 1.36 & 33.96 & 0.30 & 2.42 & 60.4 & 0.21 & 4.30 & 107.4 \\
\hline
\end{tabular}

sults represented in table 2 .

Table 2 shows results of the checker board assay for determination of MIC of the antibiotics AP \& AM and its combination $\mathrm{AP}+\mathrm{AM}$ against clinical strain of MRSA. $\mathrm{AP}$ and $\mathrm{AM}$ exhibited MIC at concentration of $57.35 \mu \mathrm{g} /$ $\mathrm{ml}$ and $800.6 \mu \mathrm{g} / \mathrm{ml}$ respectively. Whereas, AP + AM as a combination has shown a significant reduction in the required effective concentration of AP and AM which is $5 \mu \mathrm{g} / \mathrm{ml}$ and $107 \mu \mathrm{g} / \mathrm{ml}$ respectively. This shows that $\mathrm{AP}$ and AM exhibits a lesser synergistic effect when put together as a combination (AP + AM), thereby, exhibiting only a slight increase in the antibacterial potency against MRSA.

The CI values of the combined drugs were calculated. According to the results less synergistic interactions was derived for AP + AM (0.2 to 0.5).

Graphical representation of dose effect curve, logarithmic combination index, dose reduction index and isobologram for each test sample and its combination has been presented in figure $1 \mathrm{a}, \mathrm{b}, \mathrm{c} \& \mathrm{~d}$.

Logarithmic combination index plot for $\mathrm{AP}+\mathrm{AM}$ in-

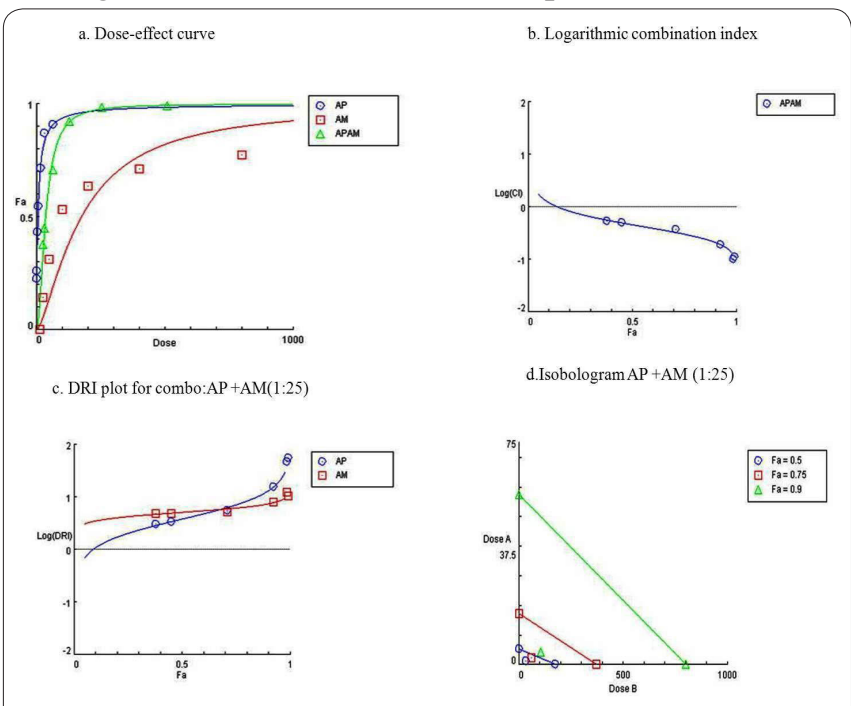

Figure 1. Combination index determination forAP, AM and $\mathrm{AP}+\mathrm{AM}$ against MRSA. All values are represented as triplicate values. A) Dose-effect curve; b) Logarithmic combination index; c) DRI plot for combo:AP+AM(1:25); d) Isobologram AP +AM (1:25).

All the values represent triplicate values.

$\mathrm{CI}<1$ indicates synergism, $\mathrm{CI}=1$ indicates additive effect, $\mathrm{CI}>1$ indicates antagonism

AM combines with AP, MIC reduced to $1 / 7$ of the MIC of AM and 1/13 of the MIC of AP $(107 \mu \mathrm{g} / \mathrm{ml}$ with $4.3 \mu \mathrm{g} / \mathrm{ml})$. 
Table 3. Combination Index value determined for CEF, AP and CEF+AP against MRSA.

\begin{tabular}{|c|c|c|c|c|c|c|c|c|c|}
\hline \multirow[b]{2}{*}{$\begin{array}{c}\text { Drug/Combination } \\
\text { against MRSA }\end{array}$} & \multicolumn{3}{|c|}{ Fraction affected $50 \%$} & \multicolumn{3}{|c|}{ Fraction affected $75 \%$} & \multicolumn{3}{|c|}{ Fraction affected $90 \%$} \\
\hline & $\begin{array}{l}\text { CI value } \\
\text { (FIC) }\end{array}$ & $\begin{array}{r}\text { Drug co } \\
\text { in }\end{array}$ & ration & $\begin{array}{c}\text { CI value } \\
\text { (FIC) }\end{array}$ & $\begin{array}{r}\text { Drug c } \\
\text { in }\end{array}$ & $\begin{array}{l}\text { ration } \\
\text { I }\end{array}$ & $\begin{array}{c}\text { CI valve } \\
\text { (FIC) }\end{array}$ & Drug co & ation in \\
\hline $\mathrm{CEF}$ & & 0.87 & & & 7.15 & & & 35.68 & \\
\hline $\mathrm{AP}$ & & & 5.20 & & & 17.26 & & & 57.35 \\
\hline CEFAP & 0.19 & 0.11 & 0.33 & 0.17 & 0.53 & 1.59 & 0.18 & 2.57 & 7.71 \\
\hline
\end{tabular}

All the values represented as triplicate values

$\mathrm{CI}<1$ indicates synergism, $\mathrm{CI}=1$ indicates additive effect, $\mathrm{CI}>1$ indicates antagonism

The CEF combines with AP, the MIC reduced to $1 / 23$ of the MIC of CEF and 1/7 of the MIC of AP (2.6 with $7.7 \mu \mathrm{g} / \mathrm{ml}$ ).

dicates combination index point below the diagonal line indicates better synergistic effects and DRI $>1$ indicates favourable dose reduction.

Isobolograms for $50 \%, 75 \%$ and $90 \%$ inhibition are shown in figure 1d. Combination data point lower left of the diagonal line indicates synergism. In the present combination of $\mathrm{AP}+\mathrm{AM}, \mathrm{IC}_{90}, \mathrm{IC}_{75}$ and $\mathrm{IC}_{50}$ showed the synergistic observations.

\section{Synergistic effect determined for CEF, AP and CEF+AP against MRSA}

The bacterial growth inhibitory effect of CEF, AP and $\mathrm{CEF}+\mathrm{AP}$ on MRSA was observed and interpreted. From the following formula, fraction affected and fraction unaffected was calculated and the dose effect curve was plotted using isobologram software.

Individual

- $\mathrm{CEF}-0.125$ to $32 \mu \mathrm{g} / \mathrm{ml}$

- AP - $1-256 \mu \mathrm{g} / \mathrm{ml}$

Combination

- $\quad \mathrm{CEF}+\mathrm{AP}(1: 3)-0.125-16 \mu \mathrm{g} / \mathrm{ml}$ of CEF with $0.375-48 \mu \mathrm{g} / \mathrm{ml}$ of AP

Table 3 shows results of the Checker Board assay for determination of MIC of the antibiotics CEF \& AP and its combination $\mathrm{CEF}+\mathrm{AP}$ against clinical strain of MRSA. CEF and AP exhibited MIC at concentration of $35.68 \mu \mathrm{g} / \mathrm{ml}$ and $57.35 \mu \mathrm{g} / \mathrm{ml}$ respectively. Whereas, $\mathrm{CEF}+\mathrm{AP}$ as a combination has shown a significant reduction in the required effective concentration of CEF and AP which is $3 \mu \mathrm{g} / \mathrm{ml}$ and $8 \mu \mathrm{g} / \mathrm{ml}$ respectively. This shows that $\mathrm{CEF}$ and $\mathrm{AP}$ exhibits a lesser synergistic effect when put together as a combination (CEF + AP), thereby, exhibiting only a slight increase in the antibacterial potency against MRSA.

The CI values of the combined drugs were calculated. According to the results less synergistic interactions was derived for $\mathrm{CEF}+\mathrm{AP}(0.17$ to 0.19$)$.

Graphical representation of dose effect curve, logarithmic combination index, dose reduction index and isobologram for each test sample and its combination has been presented in figure $2 \mathrm{a}, \mathrm{b}, \mathrm{c} \& \mathrm{~d}$.

Dose effect curve was plotted using OD value in figure 2a, with help of the curve $\mathrm{x}$ intercept, $\mathrm{y}$ intercept and median effect of the dose was calculated. Logarithmic combination index plot for $\mathrm{CEF}+\mathrm{AP}$ in figure $2 \mathrm{~b}$ indicates combination index point below the diagonal line indicates good synergistic effects and DRI $>1$ in figure $2 \mathrm{c}$ indicates favourable dose reduction.

Isobolograms for $50 \%, 75 \%$ and $90 \%$ inhibition are shown in figure $2 \mathrm{~d}$. Combination data point on the lower left indicates synergism. In the present combination of
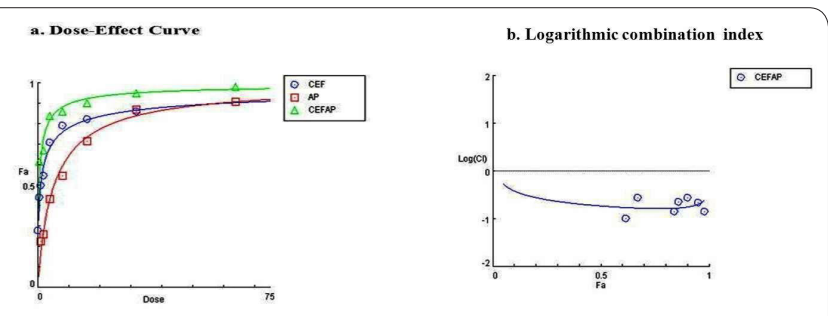

c. DRI plot for combo: $\mathrm{CEF}+\mathrm{AP}(1: 3)$
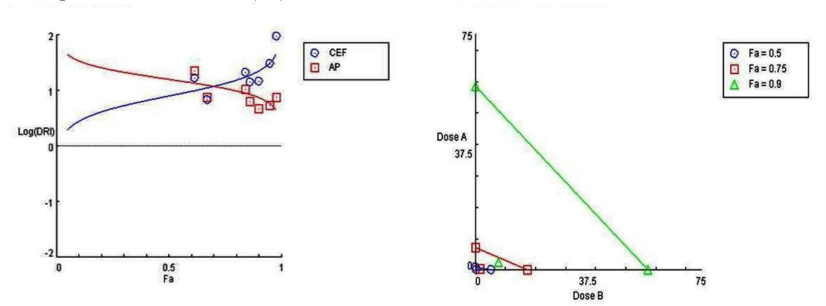

Figure 2. Combination Index determination for CEF with AP against MRSA. All values are represented as triplicate values. a) Dose-effect curve; b) Logarithmic combination index; c) DRI plot for combo: $\mathrm{CEF}+\mathrm{AP}(1: 3)$; d) Isobologram $\mathrm{CEF}+\mathrm{AP}(1: 3)$.

$\mathrm{CEF}+\mathrm{AP}, \mathrm{IC}_{90}, \mathrm{IC}_{75}$ and $\mathrm{IC}_{50}$ showed synergistic effect.

\section{Bactericidal efficacy determined against MRSA by time-kill curve assay}

To confirm the synergistic effect of AP the selected antibiotics (AM \& CEF) and their combination AM + $\mathrm{AP}$ and $\mathrm{CEF}+\mathrm{AP}$ on inhibition of MRSA, time-kill assay was performed. Figure 3 . show the results of the time-kill assay against clinical MRSA. AM, CEF and AP individually induced bacterial cell death upto $18 \mathrm{~h}$ incubation, i.e 2 X MIC of $800 \mu \mathrm{g} / \mathrm{ml}$ of AM, $35 \mu \mathrm{g} / \mathrm{ml}$ of CEF, $60 \mu \mathrm{g} / \mathrm{ml}$ of AP individually, when used together in the proportion the combination of $100 \mu \mathrm{g} / \mathrm{ml}$ of

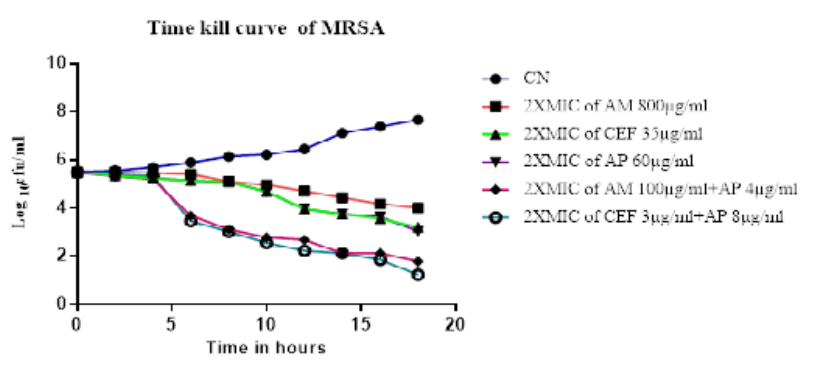

Figure 3. Determination of bactericidal efficacy of AM, CEF, $\mathrm{AM}+\mathrm{AP}$ and $\mathrm{CEF}+\mathrm{AP}$ against MRSA by Time-kill curve assay. The effect of ampicillin, ceftriaxone alone and in combination the viable counts of MRSA. 2MIC; $800 \mu \mathrm{g} / \mathrm{ml}$ of AM, $35 \mu \mathrm{g} / \mathrm{ml}$ of CEF, $60 \mu \mathrm{g} / \mathrm{ml}$ of AP individually and the combination of $100 \mu \mathrm{g} / \mathrm{ml}$ of AM with $5 \mu \mathrm{g} / \mathrm{ml}$ of AP, $3 \mu \mathrm{g} / \mathrm{ml}$ of CEF with $8 \mu \mathrm{g} / \mathrm{ml}$ of AP the values plotted are the means of 3 observations, standard errors of the means. $\mathrm{P}<0.001$ compared to control group. 
AM with $5 \mu \mathrm{g} / \mathrm{ml}$ of AP, $3 \mu \mathrm{g} / \mathrm{ml}$ of CEF with $8 \mu \mathrm{g} / \mathrm{ml}$ of AP a reduction of over $2 \log 10$-fold in the bacterial count occurred after $6 \mathrm{~h}$ onwards. $\mathrm{CEF}+\mathrm{AP}$ effectively inhibited the growth of MRSA. The results of the timekill assays of the two drug combinations AM +AP and $\mathrm{CEF}+\mathrm{AP}$ against MRSA showed significant inhibitory effect and reduced the colony count by approximately $99 \%$ after $6 \mathrm{~h}$. The low bactericidal effect of AM and CEF induced us to combine it with other antibacterial agents. AP dramatically enhanced the activity of AM and CEF and lowered the number of CFUs. The two drug combinations AM + AP and $\mathrm{CEF}+\mathrm{AP}$ used were considered bactericidal at the lowest concentration that reduced the original inoculum by $2 \log 10 \mathrm{CFU} / \mathrm{ml}$ (99.9\%) for each of the indicated times.

\section{Inner Membrane Permeability Assay of AM and CEF with AP Against MRSA}

The IM permeability assay result for AM, CEF, AP, $\mathrm{AM}+\mathrm{AP}, \mathrm{CEF}+\mathrm{AP}$ shows in Figure. 4 where cell lysis was measured by UV-absorption of released cellular contents post lysis from MRSA cells at $260 \mathrm{~nm}$. After treatment with $800 \mu \mathrm{g} / \mathrm{ml}$ of AM, $35 \mu \mathrm{g} / \mathrm{ml}$ of CEF, $50 \mu \mathrm{g} /$ $\mathrm{ml}$ of AP individually and the combination of $100 \mu \mathrm{g} /$ $\mathrm{ml}$ of AM with $5 \mu \mathrm{g} / \mathrm{ml}$ of AP, $3 \mu \mathrm{g} / \mathrm{ml}$ of CEF with 8 $\mu \mathrm{g} / \mathrm{ml}$ of AP the OD value was increased considerably compared to control and CP. The inner membrane of MRSA was permeabilized more rapidly by the CEF + AP combination compared to other groups. CP, which is highly active against the inner membrane, showed inner membrane permeability slightly lower than CEF + AP combination, produce significant difference $(p<$ $0.001)$. This effect was due to the leakage of intracellular contents that was released more rapidly, thereby absorption at $260 \mathrm{~nm}$ was increased. This effect was a significant difference compared to control.

\section{Outer Membrane Permeablitiy assay for AM, CEF with AP treated MRSA cells}

The percentage of crystal violet uptake into the MRSA cell membrane post lysis has been determined by

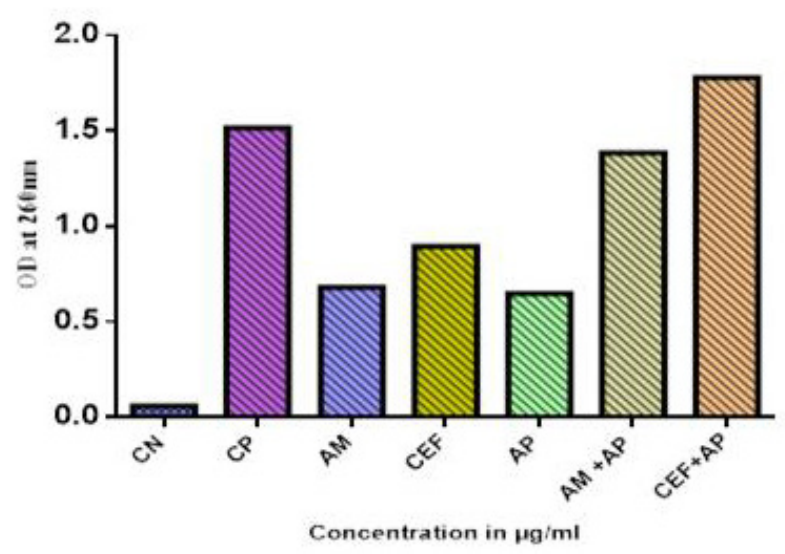

Figure 4. Inner membrane permeability assay for AM, CEF, AP, $\mathrm{AM}+\mathrm{AP}, \mathrm{CEF}+\mathrm{AP} .800 \mu \mathrm{g} / \mathrm{ml}$ of AM, $35 \mu \mathrm{g} / \mathrm{ml}$ of CEF, $50 \mu \mathrm{g} / \mathrm{ml}$ of AP individually and the combination of $100 \mu \mathrm{g} / \mathrm{ml}$ of AM with $5 \mu \mathrm{g} / \mathrm{ml}$ of AP, $3 \mu \mathrm{g} / \mathrm{ml}$ of CEF with $8 \mu \mathrm{g} / \mathrm{ml}$ of AP treated against MRSA, CP-Ciprofloxacin at $2 \mu \mathrm{g} / \mathrm{ml}$ was used as positive control and untreated cells were used as negative control. The mean \pm SE for three replicates are illustrated. Means sharing the same superscript are not significantly different from each other $(\mathrm{p}<0.001)$.
Outer memb rane permeability assay

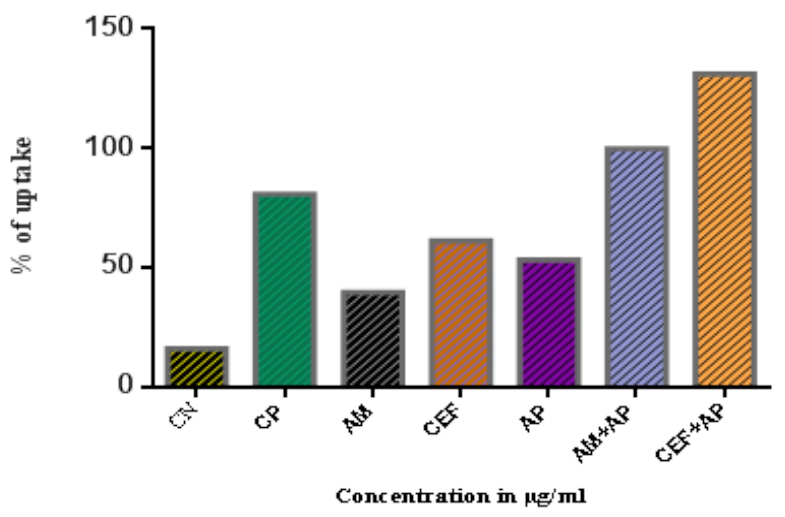

Figure 5. Outer membrane permeablitiy assay for AM, CEF with AP treated MRSA cells. AM- MIC; $800 \mu \mathrm{g} / \mathrm{ml}$ of AM, $35 \mu \mathrm{g} / \mathrm{ml}$ of $\mathrm{CEF}, 50 \mu \mathrm{g} / \mathrm{ml}$ of AP individually and the combination of $100 \mu \mathrm{g} /$ $\mathrm{ml}$ of AM with $5 \mu \mathrm{g} / \mathrm{ml}$ of AP, $3 \mu \mathrm{g} / \mathrm{ml}$ of CEF with $8 \mu \mathrm{g} / \mathrm{ml}$ of AP treated against MRSA. Crystal violet uptake of untreated cells used as control. Ciprofloxacin at $2 \mu \mathrm{g} / \mathrm{ml}$ was used as positive control and untreated cells were used as negative control. The mean $\pm \mathrm{SD}$ for three replicates are illustrated. The graph shows $\%$ of crystal violet uptake of each treatment at $60 \mathrm{~min}$.

UV absorption at $590 \mathrm{~nm}$. According to the final graph, all the test samples AM, CEF, AM + AP and CEF + AP exhibited cell wall damage to an extent as shown in Figure 5. With $\mathrm{CEF}+\mathrm{AP}$, the crystal violet uptake was considerably higher than control and CP. Percentage of crystal violet uptake into the MRSA cell membrane for all other test samples i.e. AM, CEF and AM + AP were significantly high compared to that of the standard CP. From the above results it can be corrugated that the outer membrane permeability was high compared to inner membrane permeability of all the tested combinations. This OM permeabilisation might responsible for antibacterial activity.

\section{Scanning electron micrographs of MRSA treated with test agents $\mathrm{AM}+\mathrm{AP}$ and $\mathrm{CEF}+\mathbf{A P}$}

SEM observation was carried out in order to evaluate the percentage of cell wall damage caused due to test agents. SEM of control MRSA and those treated with $\mathrm{AM}+\mathrm{AP}$ and $\mathrm{CEF}+\mathrm{AP}$ are shown in Figure $6 \mathrm{a}-\mathrm{f}$. Visualization of the ultrastructure in general revealed marked morphological changes in MRSA treated with $\mathrm{AM}+\mathrm{AP}$ and $\mathrm{CEF}+\mathrm{AP}$.

\section{TEM for MRSA cells treated with AM + AP and CEF $+\mathbf{A P}$}

Figure 7 a-f shows the appearance of normal log phase cells of MRSA with cell division. The outer membrane and the cytoplasmic membrane can be distinguished. The TEM image of MRSA after exposure to CEF with AP shows some of these bacterial cells exhibited gap between outer membrane and cytoplasmic membrane (Figure. 7 a-f). The MRSA cells treatment with $3 \mu \mathrm{g} / \mathrm{ml}$ CEF with AP $8 \mu \mathrm{g} / \mathrm{ml}$ are shown in Figure 7c. Most of the bacterial cells were damaged after treatment with $\mathrm{AM}+\mathrm{AP}$ and $\mathrm{CEF}+\mathrm{AP}$. The result showed that CEF $3 \mu \mathrm{g} / \mathrm{ml}$ in combination with $8 \mu \mathrm{g} / \mathrm{ml}$ of AP also caused marked morphological damage, cell wall, cell shape and losing most organelles in MRSA as 


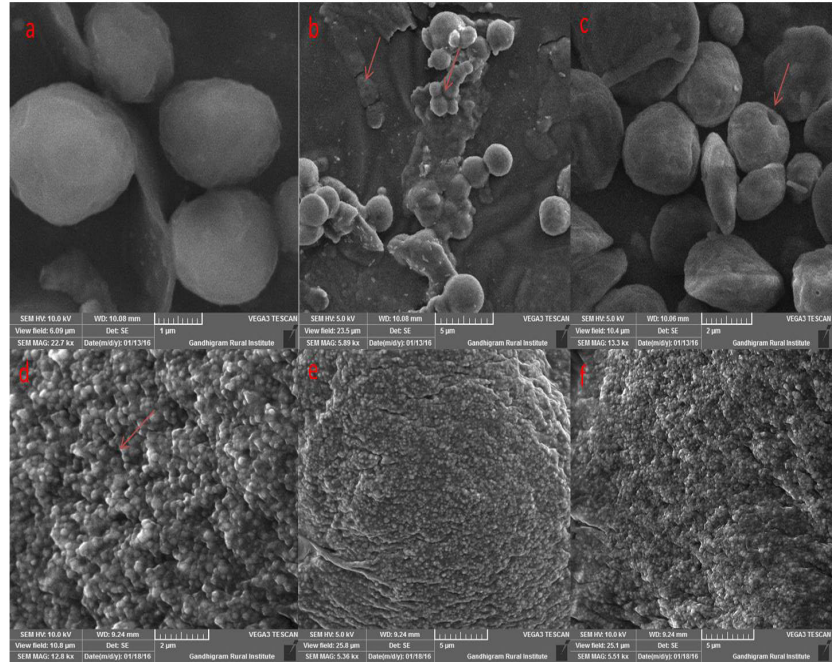

Figure 6. Scanning electron micrographs showing reduction of MRSA growth after $36 \mathrm{~h}$ incubation with $\mathrm{AM}+\mathrm{AP}$ and $\mathrm{CEF}+$ AP. a) Control-Untreated cells; (b \& c) Cell disruption by Pore formation in $\mathrm{AM}+\mathrm{AP}$ treated cells; $(\mathrm{d}$, e \& $\mathrm{f})$ deformation of cell structure in $\mathrm{CEF}+\mathrm{AP}$ treated cells.

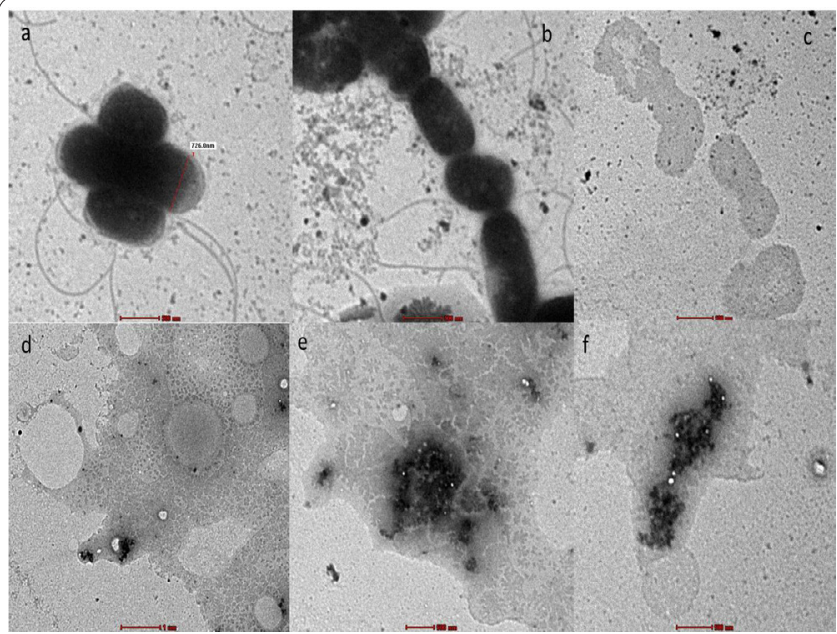

Figure 7. a-f TEM image of $\mathrm{AM}+\mathrm{AP}$ and $\mathrm{CEF}+\mathrm{AP}$ treated MRSA cells. a,b- Untreated MRSA cells; c,d- Ampicillin with Apigenin treated cells; e,f- Ceftriaxone with apigenin treated cells.

shown in Figure 7a-f.

\section{Discussion}

Bacterial infections are a worldwide burden and treatment of patient with traditional antibiotics is becoming increasingly challenging or ineffective. Natural products can be used as raw materials in the development of new antibacterial substances. Antibacterial screening of medicinal compounds has been used as therapeutic agents. In earlier literature reported that curcumin was obtained from $c$.longa which was shown synergistic activity against gram $(+)$ ve and gram (-) ve especially against MRSA (16).

The experiments in summary deals with 1) evaluation of antibacterial effects of phenolic flavonoid AP 2 ) investigation of possible synergistic action of AP in combination with $\beta$-lactam antibiotics AM and CEF 3) study of membrane permeabilisation caused by the test agents on MRSA using IM and OM assay.

In the present study, antibacterial activity of AP against gram (+) ve and gram (-) ve organism was $32.5-250 \mu \mathrm{g} / \mathrm{ml}$. Earlier reports of apigenin, naringenin, thymoquinone have great antimicrobial activity and their mechanism of activity also studied in detail (17). The antibacterial activity of flavone Apigenin was due in part to their inhibition of DNA gyrase explained in TP.Tim cushnie et al 2005 (18).

The synergistic combination of AP with AM and CEF was varied this was much lower than their own MIC. To confirm their CI values against MRSA a time kill assay was conducted. This finding indicated that this CI effect may overcome the problem associated with some MRSA pathogen when used in a combination with commonly used antibiotics AM and CEF. The results of this combination were an agreement with earlier literature artocarpin may be used to enhance the antibacterial activities of the antibiotics AM. Flavonoids are well known to possess antibacterial activity with many possible mechanism of action i.e reduction of membrane fluidity due to interaction of flavonoids with the lipophilic side of cell membrane (15). The antibacterial effect of selected flavonoid has 5,7-OH group of A ring and 1,4-OH group of the B ring in AP are important for synergistic activity with selected antibiotics (10).

The checkerboard analysis showed the synergistic effects of $\mathrm{AM}+\mathrm{AP}$ and $\mathrm{CEF}+\mathrm{AP}$ combination against MRSA with CI index between 0.18-0.47. From the results, it can be confirmed that AM + AP as a combination has synergistic action, whereas CEF + AP showed higher synergistic effect. The addition of AP to AM and CEF significantly altered the individual effect of both compounds against MRSA. This activity was compared with an earlier finding that implied that the two additional hydroxyl groups on the structure of quercetin derivative might facilitate its inhibitory activity (19).

Time kill assay of AM + AP and CEF + AP provided a standard platform to observe kinetics of antibacterial action of all the test agents against MRSA. About $99 \%$ MRSA inhibition was observed at $8 \mathrm{~h}$. Therefore, it is assumed that the improved antibacterial efficacy of the tested combinations might be because of the synergistic effect of AP on AM and CEF. This may be attributed to the fact that AP possesses antibacterial properties that contributed to the observed activities either alone or in combination treatment. These antibacterial properties may have several mechanisms of action that affects MRSA growth. The results of this combination were in agreement with earlier literature on artocarpin that was used to enhance the antibacterial efficiency of the antibiotic drug AM. Flavonoids are well known to possess antibacterial activity with many possible mechanism of action for example, reduction of membrane fluidity due to interaction of flavonoids with the lipophilic portion of the cell membrane (15). Investigation on mode of action has shown that these compounds cause cell lysis leading to bacterial death in S. aureus species (19). Assessment of MIC values revealed that the selected apigenin and its combination have anti-MRSA activity. The synergistic impact of AP individually combined with AM and CEF has been crucial in suppressing MRSA growth.

The inner membrane permeability results provide evidence that mechanism of action of AP is damage of cytoplasmic membrane thereby increasing its non-specific permeability (13). This hyper permeability may be followed by release of UV-absorbing materials, which is the index of cell lysis and non-selective pore formation that leads to leakage of ions. This was confirmed 
with measurement of OD $(260 \mathrm{~nm})$ of the resulting samples which consist of deformed cellular organelles, macromolecules and cell membrane. The results seem to be compared with previous findings that E.coli outer membrane was significantly changed by amoxicillin plus galangin combination or peptide-peptide nucleic acid conjugate OD at $260 \mathrm{~nm}(10,20,21,22)$.

The outer membrane permeability by the crystal violet assay showed that the membrane of S.aureus was significantly altered by the combinations of AM + AP and CEF + AP, compared to control. The effect of AP on outer membrane permeability was evidenced by the percentage uptake of the dye crystal violet. Usually, crystal violet penetration into the outer membrane is very poor, but when the membrane is defective the rate of penetration is higher (13). A significant enhancement in the intake of crystal violet in comparison with the control cells and MRSA treated with AM and CEF alone was observed in MRSA treated AM + AP and CEF + AP. This shows that AM and CEF has low antibacterial efficacy individually, whereas, AP alters membrane permeability and makes the cells, which generally are less permeable, hyper permeable to extracellular components $(10,13)$. These results seem consistent with reported findings that the outer membrane of E. coli was significantly altered by the combination of amoxicillin plus galangin and peptide-peptide nucleic acid conjugate $(20,21,22)$. The antibacterial activity of selected combination is mainly due to OM permeability than IM permeability. SEM reports are in agreement with the earlier report determining the morphology of the bacteria after treatment with the C.longa extract (23). TEM results of $\mathrm{AM}+\mathrm{AP}$ and $\mathrm{CEF}+\mathrm{AP}$ treated cells demonstrated that MRSA cells exhibited marked morphological damage and reduction in average cell areas significantly lesser than control. These results seem consistent with previous findings that the combination of ceftazidime plus galangin caused damage to the ultra-structures of the cells, affected the integrity of the cell walls, and led to an increase in cell size of ceftazidime-resistant $S$. aureus (10).

Hence, AP when used in combination with AM and $\mathrm{CEF}$ at this concentration may have a sufficient margin of safety for therapeutic use. In summary, our study provides evidence that AP has the potential to reverse bacterial resistance to originate traditional drug susceptibility of it.

The results of the present study provided scientific explanation for the use of AP. Our findings provide evidence that AP have the synergistic effect with AM, $\mathrm{CEF}$ to reverse bacterial resistance. This is the first ever report on the anti-MRSA activity and the mode of bacterial inhibition of AP individually and in combination with $\mathrm{AM}$ and $\mathrm{CEF}$. The grade of antibacterial activity indicated that $\mathrm{AP}$ is a potential source that could be helpful for the development of new antibacterial agents capable of lessening the burden of drug resistance, cost of management of disease, to allow lower doses of antibiotic to reduce toxicity and without the need of one more antibiotics. Overall, AP offer for the development of a valuable adjunct to AM, CEF against these MRSA strains.
Acknowledgements

The authors gratefully acknowledge the financial grant awarded by the Department of Science and Technology, Ministry of Science and Technology, Government of India, in the form of facility project 'National facility for Drug Development for Academia, Pharmaceutical and Allied industries' (VI-D\&P/349/10-11/TDT/1, dt.21.10.2010).

\section{References}

1. Snider J, Rivard B. Methicillin-resistant Staphylococcus aureus: A review of Current Antibiotic Therapy. Spectrum Health Grand Rapids Michigan 2012; pp.1-25.

2. Al-Talib HI, Yean CY, Al-Jashamy K, Hasan H. Methicillin-resistant Staphylococcus aureus nosocomial infection trends in Hospital Universiti Sains Malaysia during 2002-2007. Ann. Saudi. Med. 2007; 30(5): 358-63.

3. Ghaznavi-Rad E, Nor Shamsudin M, Sekawi Z, Khoon LY. Predominance and emergence of clones of hospital-acquired methicillin-resistant Staphylococcus aureus in Malaysia. J. of Clin. Microb. 2010; 48(3): 867-72.

4. Yothin T, Nongluk A, Sirichaiwetchakoon K, Krubphachaya P, Kupittayanant S, Eumkeb G. Synergistic activity and mechanism of action of Stephania suberosa Forman extract and Ampicillin combination against Ampicillin-resistant Staphylococcus aureus. J. of Biomed.Sci. 2014; 21: 90.

5. Issam AL-Ani, Stefan Z, Jurgen R, Michael W. Pharmacological synergism of bee venom and melittin with antibiotics and plant secondary metabolites against multi-drug resistant microbial pathogens. Phytomedicine 2015; 22:11

6. Rasha AA, Hatil HA, Aisha ZA. Synergistic Antibacterial Interaction between Trachyspermum ammi, Senna alexandrina Mill and Vachellia nilotica spp. Nilotica Extract and Antibiotics. Pak. J. of Biol. Sci. 2015; 18 (3): 115-121.

7. Mun, SH, Joung DK, Kim YS, Kang OH, Kim SB, Seo YS et al. Synergistic antibacterial effect of curcumin against methicillin-resistant Staphylococcus aureus. Phytomedicine 2013; 20: $714-8$

8. Alsaba F, Furqan A, Inshad AK, Abdul SS, Daljit SA, Bhahwal AS et al. Anti-staphylococcal and biofilm inhibitory activities of acetyl-11-keto-b -boswellic acid from Boswellia serrata. BMC Microbiology 2011; 11:54.

9. Tsao SH, Hsu CC, Yin MC. Garlic extract and two diallyl sulphides inhibit methicillin-resistant Staphylococcus aureus infection in BALB/c mice. J. of Antimicrob.Chemo. 2003; 52: 974-980.

10. Eumkeb G, Somnuk C. Synergistic activity and mechanism of action of ceftazidime and AP combination against ceftazidime-resistant Enterobacter cloacae. Phytomedicine 2013; 20: $262-269$.

11. Cappuccino J, Sherman N. Antimicrobial susceptibility procedure. In: Practical microbiology manual. 5th edn. New York, Benjamin/Cummings Science Publishing 2002; 254-56.

12. Chou TC and Talalay P.Analysis of combined drug effects: A new look at a very old problem. Trends Pharmacol. Sci 1983; 450454.

13. Devi KP, Arif Nisha S, Sakthivel R, Pandian SK. Eugenol (an essential oil of clove) acts as antibacterial agents against salmonella typhi by disrupting the cellular membrane. Journal of J.Ethnopharmacol. 2010; 130: 107-115.

14. Akilandeswari K, Ruckmani K. Antibacterial potentiality of antiulcer and antispasmodic drugs with selected antibiotics against methicillin resistant Staphylococcus aureus: In vitro and in silico studies. Bangladesh J Pharmacol 2015; 10: 875-883. 
15. Abdi WS, Pharkphoom P. Synergistic effect of artocarpin on antibacterial activity of some antibiotics against methicillin-resistant Staphylococcus aureus, Pseudomonas aeruginosa, and Escherichia coli. Pharm Biol 2015; 1-6.

16. Rathna C, Sayani M, Sauradip S, Sreedipa B, Sanjukta D, Hemanta K. Antimicrobial activity of Sesbania grandifolra flower polyphenol extracts on some pathogenic bacteria and growth stimulatory effect on the probiotic organism Lactobacillus acidophilus. Micobiol. Res. 2012; 167: 500-506.

17. Kamel C, Bochra K, Hanene J, Kacem M, Amina B. Antibacterial activity of Thymoquinone, an active principle of Nigella sativa and its potency to prevent bacterial biofilm formation. BMC Complement. Altern. Med. 2011; 11:29

18. Tim Cushnie TP, Lamb AJ. Antimicrobial activity of flavonoids. Int. J. Antimicro. Ag. 2005; 26: 343-356

19. Wu D, Kong Y, Han C, Chen J. d-Alanine:d-alanine ligase as a new target for the flavonoids quercetin and apigenin. Int. J. Antimi- cro. Ag. 2008; 32: 421-426.

20. Eriksson M, Nielsen PE, Good L. Cell permeabilization and uptake of antisense peptide-peptide nucleic acid (PNA) into Escherichia coli. J. of Biol. Chem. 2002; 277: 7144-7147.

21. Eumkeb G, Siriwong S, Phitaktim S, Rojtinnakorn N. Synergistic activity and mode of action of flavonoids isolated from smaller galangal and amoxicillin combinations against amoxicillin-resistant Escherichia coli. J. of App. Microb. 2012; 112: 55-64.

22. Eumkeb G, Siriwong S, Thumanu K. Synergistic activity of luteolin and amoxicillin combination against amoxicillin-resistant Escherichia coli and mode of action', J. of Photochem.Photobiol.2012; 117: 247-253.

22. Ankur, G., Surabhi, M., Rajendra, S.: Evaluation of antimicrobial activity of Curcuma longa rhizome extract against Staphylococcus aureus. Biotechnology reports, 2015; 6: 51-55. 